\title{
BUCKLING AND POSTBUCKLING BEHAVIOUR OF STAINLESS STEEL STAYED DOUBLE CROSSARM PRESTRESSED COMPRESSION ELEMENTS
}

\author{
R. Pichal ${ }^{*}$, J. Machacek ${ }^{* *}$
}

\begin{abstract}
Prestressed stayed columns with two crossarms are investigated for stability and maximal loading capacity. First, analytical geometrical derivation of minimal and maximal critical loading under optimal prestressing is presented. Second, geometrically nonlinear analysis with imperfections (GNIA) using ANSYS software is employed to receive numerical values of critical and maximal loading of "nearly perfect", ideal column. Finally, imperfect column with large initial deflections corresponding to Eurocode demand is investigated for various prestressings. In the conclusion, the comparison of analytical and numerical values is provided and comparison of the same specific column with either one or two crossarms is evaluated.
\end{abstract}

Keywords: stability, prestressing, two crossarms, nonlinear buckling, stainless steel.

\section{Introduction}

The paper follows-up the former Authors' investigation on the prestressed stayed columns with just one central crossarm (Pichal and Machacek, 2017, 2018, Servitova and Machacek, 2011). Based on the fundamental analytical research by Hafez et al. (1979) and further numerical analyses by Saito and Wadee (2009) and Wadee et al. (2013) the principal behaviour of prestressed stayed columns with one crossarm was adequately described and experimentally validated.

Nevertheless, designers are aware of superior behaviour of the stayed prestressed columns with more than one crossarm. Feeling the higher quality in prestressed elements with multiple crossarms they used such elements frequently in practice, see Fig. 1.
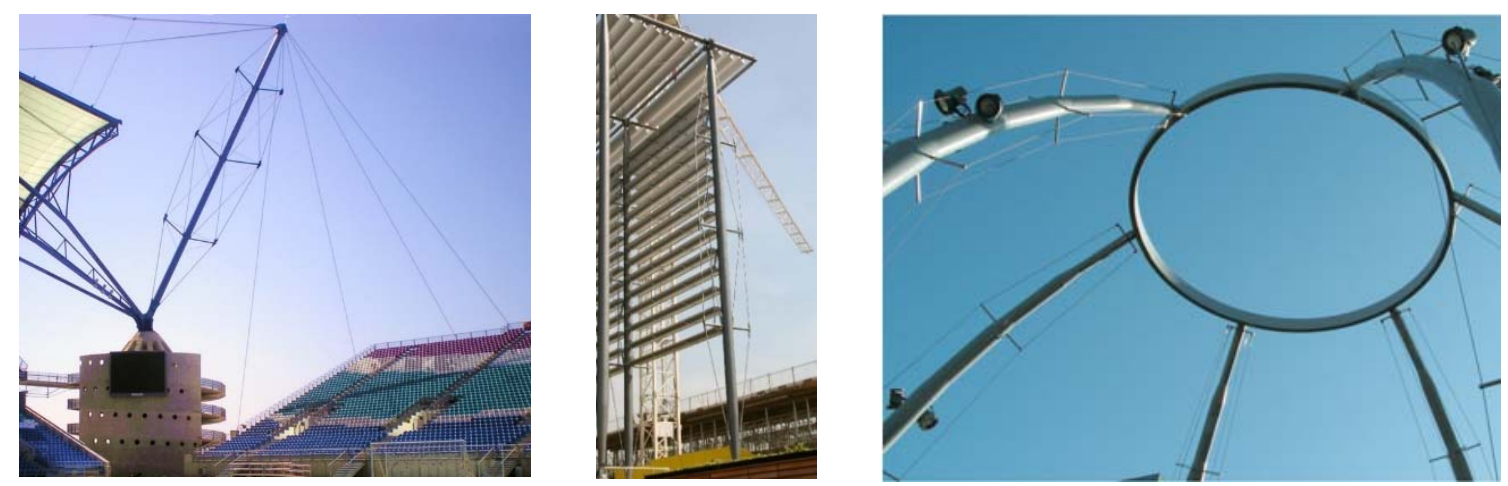

Fig. 1: Stayed column with 3 spatial crossarms (Estádio Algarve Faro), with 3 planar crossarms (London), with multiple spatial crossarms (Parc del centre del Poblenou, Barcelona).

* Ing. Radek Píchal: Czech Technical University in Prague, Faculty of Civil Engineering, Thakurova 7; 166 29, Prague; CZ, radek.pichal@fssv.cvut.cz

** Prof. Ing. Josef Macháček, DrSc.: Czech Technical University in Prague, Faculty of Civil Engineering, Thakurova 7; 166 29, Prague; CZ, machacek@fsv.cvut.cz 
Recently, a new analysis concerning stability of stayed columns with multiple-crossarm was performed by Lapira et al. (2017) and Yu and Wadee (2017), oriented to 3 crossarms, possibly supplemented by additional stays in the central bay of the column. They derived analytical expressions for maximal critical loading under corresponding optimal prestressing and analyzed imperfect central column using ABAQUS software for maximal loading.

This paper deals with prestressed stayed columns of stainless steel having two crossarms. First, the analytical formulas for the critical loading under an arbitrary prestressing of stays are derived (see Fig. 2) second, geometrically nonlinear analysis (GNIA) is presented for both critical and maximal load values.
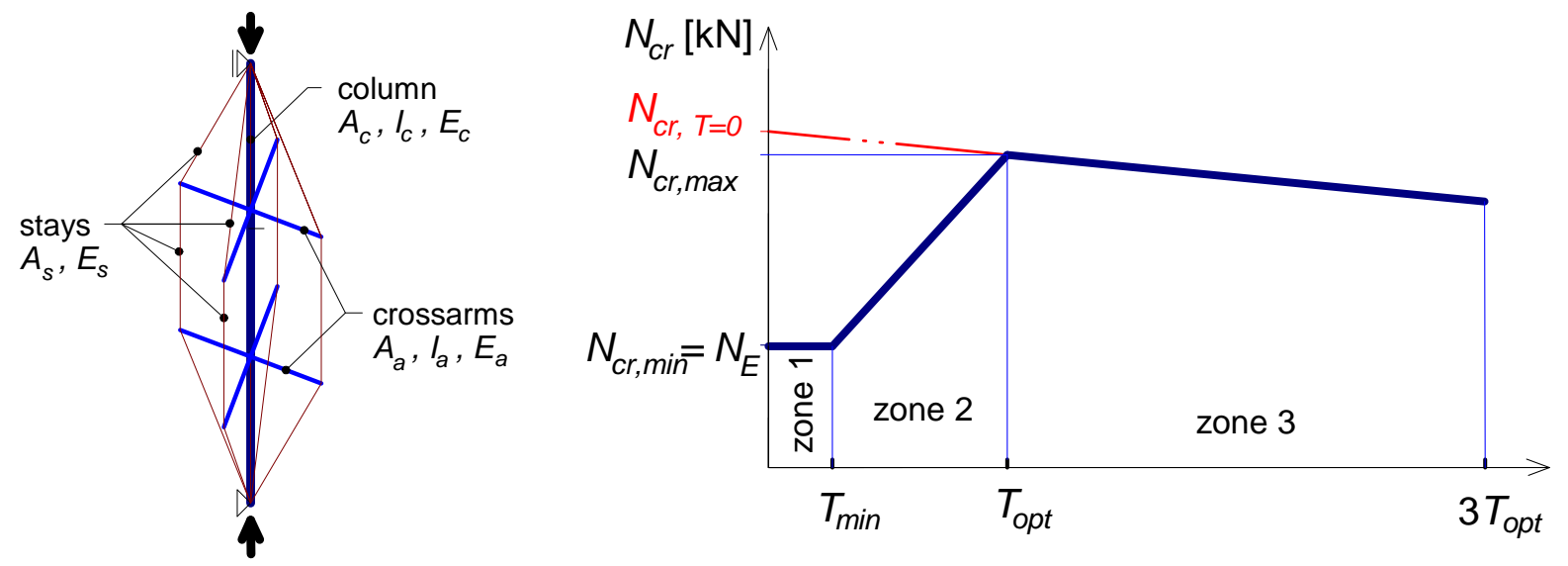

Fig. 2: Axonometry of the column with two crossarms and analytical distribution of relationship "critical loading $\left(N_{c r}\right)$ vs prestressing in each of the stays $(T)$ ".

\section{Stability of ideal columns with two crossarms}

Following the approach of stayed columns with just one crossarm provided by Hafez et al. (1979) the analytical analysis of deformations, prestressing and critical loading may be analysed. The geometry of the stayed columns under prestressing of stays is given in Fig. 3. The basic assumption concerning geometrical analysis are: 1) The column is perfectly straight and concentrically loaded. 2) The connections between column and crossarms are rigid and between the stays and column/crossarms are ideal hinges. 3) The maximal unrealistic buckling load of the stayed column is assumed to be obtained by the LBA using FEM for the column without prestressing $N_{c r, T=0}$ (see Fig. 2). 4) The axial deformations of the column and crossarms are neglected in LBA, however, need to be considered when derivation of the magnitude of tension in the stays.
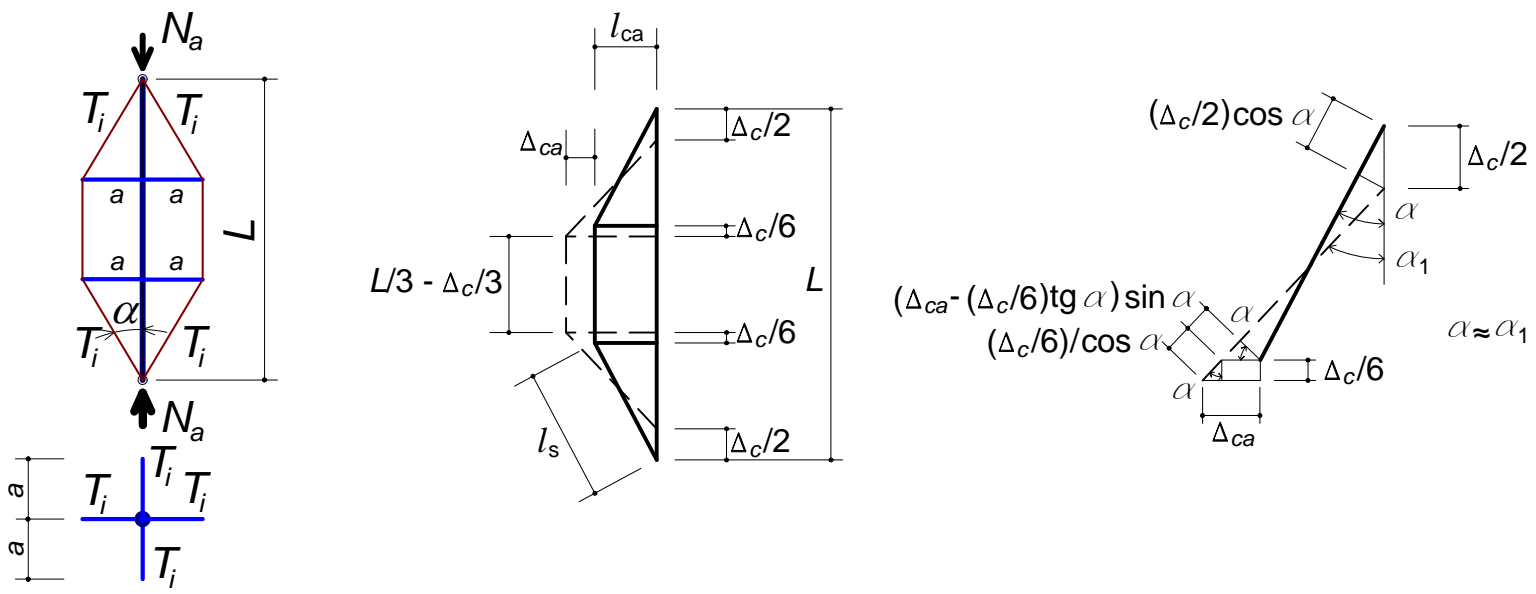

Fig. 3: Geometry of double-crossarm stayed column with two crossarms located at thirds of the column length and change in length of stays due to axial deformation.

Linear buckling analysis (LBA) using 2D SCIA Engineer software provided the critical loads and modes of buckling and are shown in Fig. 4.

The principal values resulting from the geometrical analysis and concerning the three zones presented in the Fig. 2 are as follows: 


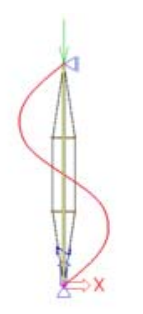

$$
N_{c r, a n t i}=44.43 \mathrm{kN}
$$

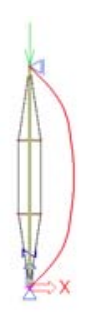

$N_{\text {cr,sym }}=72.12 \mathrm{kN}$

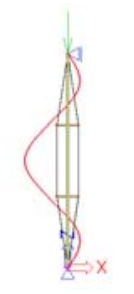

$N_{\text {cr,cell }}=91.90 \mathrm{kN}$

Fig. 4: The first three modes of the stayed column without any prestressing.

$$
\begin{gathered}
T_{\min }=N_{E} C_{1, n}=\frac{\pi^{2} E_{c} I_{c}}{L^{2}} C_{1, n} \sqrt{b^{2}-4 a c} ; \quad \text { with: } C_{1, n}=\frac{\cos \alpha}{3 K_{c}\left(\frac{1}{K_{s}}+\frac{n \cos ^{2} \alpha}{3 K_{c}}+\frac{\sin ^{2} \alpha}{K_{c a}}\right)} \\
N_{c r}=N_{E}=\frac{\pi^{2} E_{c} I_{c}}{L^{2}} ; \quad K_{c}=\frac{A_{c} E_{c}}{L} ; \quad K_{c a}=\frac{A_{a c} E_{c a}}{l_{c a}} ; \quad K_{s}=\frac{A_{s} E_{s}}{l_{s}} \\
N_{c r, \text { max }}=N_{f}=\frac{N_{c r, n, T=0}}{C_{2, n}} ; \quad \text { with: } C_{2, n}=1+\frac{n \cos ^{2} \alpha}{3 K_{c}\left(\frac{1}{K_{s}}+\frac{\sin ^{2} \alpha}{K_{c a}}\right)} \\
T_{o p t}=N_{c r, \text { max }} C_{1, n} ; \quad N_{c r, \text { zone } 3}=\left(N_{c r, \max }-n T_{i} \cos \alpha\right) C_{2, n}
\end{gathered}
$$

The formulas were applied to the same specific data of the stainless steel stayed column with just one central crossarm (Pichal and Machacek, 2017) but this time with two crossarms located in the thirds of the length: $L=5000 \mathrm{~mm}, A_{c}=302 \mathrm{~mm}^{2}, I_{c}=87009 \mathrm{~mm}^{4}, E_{c}=200 \mathrm{GPa}, a=250 \mathrm{~mm}, A_{a}=111 \mathrm{~mm}^{2}, I_{a}=7676 \mathrm{~mm}^{4}$, $E_{a}=200 \mathrm{GPa}, L_{s}=2513 \mathrm{~mm}, A_{s}=12.6 \mathrm{~mm}^{2}, E_{s, \text { ini }}=200 \mathrm{GPa}$.

Substituting into the above formulas the constants are $C_{1,4}=0.0351, C_{2,4}=1.1612$ and values:

$N_{E}=6870 \mathrm{~N} ; T_{\min }=241 \mathrm{~N} ; N_{c r, \max }=38262 \mathrm{~N} ; T_{\text {opt }}=1343 \mathrm{~N} ; N_{c r, 3 T o p t}=25925 \mathrm{~N}$

\section{GNIA for stability and maximal loading}

As noted by Pichal and Machacek (2017), due to sudden change of the inner energy of the column at instant of buckling in zone 2, LBA can't be used. Therefore ANSYS software was used for 3D GNIA and the same specific column (elements BEAM188 for the column/crossarms, LINK180 for cable stays) with meshing $L / 250$ and $a / 25$. Elastic stainless steel material with modulus of elasticity $E=200 \mathrm{GPa}$ was employed.

For stability analysis the spatial infinitesimal initial deflections in accordance with figure 5 were considered $\left(w_{0}=L / 500000=0.01 \mathrm{~mm}\right.$, i.e. $\left.w_{0 y}=w_{0 z}=w_{0} / \sqrt{ } 2\right)$.
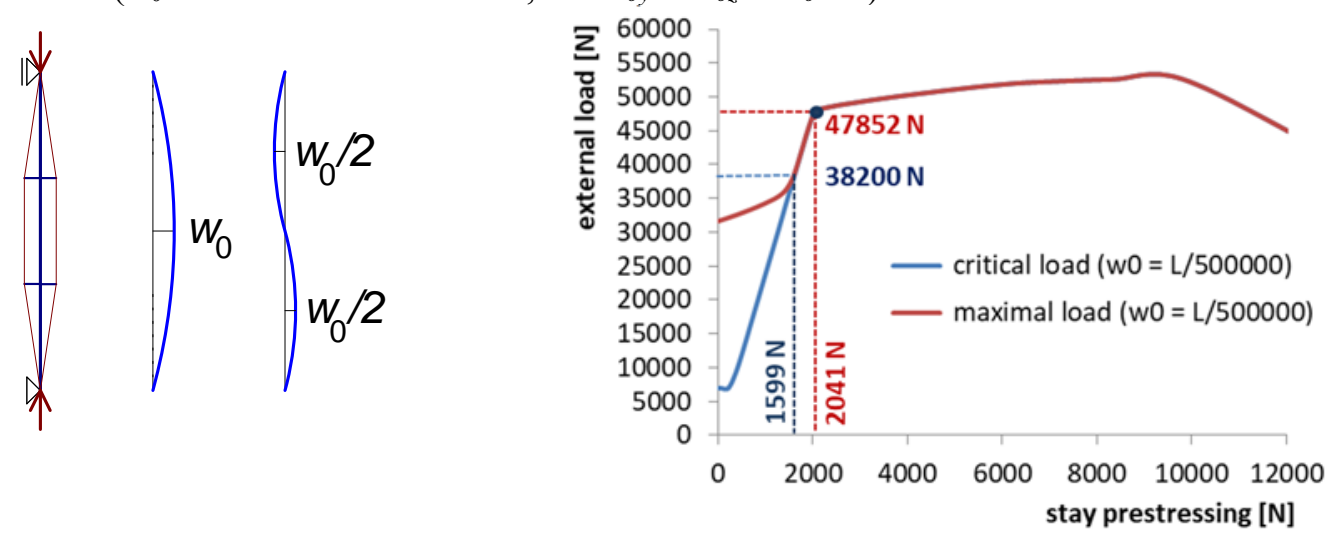

Fig. 5: Both initial deflections considered in the analysis and 3D GNIA results.

For maximal loading capacity the initial deflection $w_{0}=L / 200=25 \mathrm{~mm}$, corresponding to Eurocode EN 1993-1-1 for cold-formed tubes and elastic analysis, were considered, see Fig. 6. 

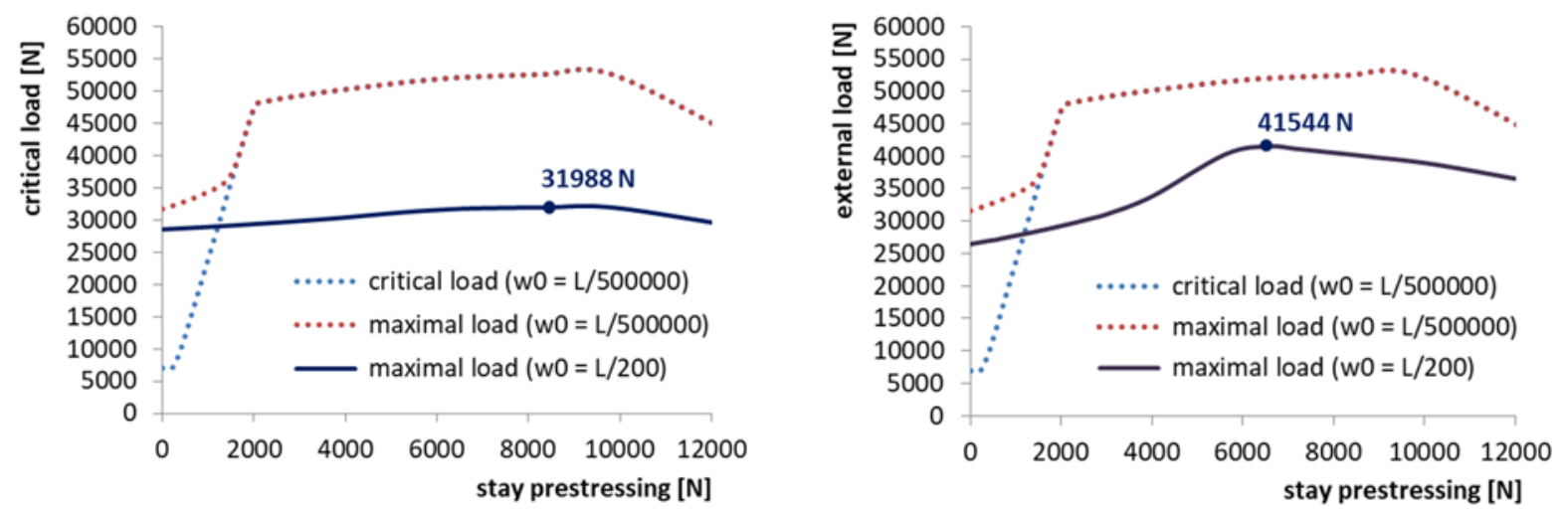

Fig. 6: Results for maximal stayed column capacity: for antisymmetrical mode of initial deflections (left), for symmetrical mode of initial deflections (right).

\section{Conclusions}

Critical and maximal loads for stainless steel stayed columns with two crossarms were investigated. General analytical formulas for critical loads and optimal prestressing were derived. For the specified data of such column the analytical values were compared with GNIA and resulted into the following conclusions:

a) Analytical values concerning "critical loadings" in the prestressed columns agree well with the GNIA up to the maximal critical loading, when activating of stays on convex side after buckling play important role. The activation of stays in tension modifies buckling modes and therefore the distribution of critical load both in zone 2 and 3 (see Fig. 5).

b) The maximal loading (Fig. 6 left) proved to be approximately $84 \%$ of the critical one.

c) Comparison shows superior behaviour of the column with two crossarms towards column with just one crossarm, resulting into increase of both critical (20.9\%) and maximal capacity (62.4\%) values.

Finally it is necessary to remark, that although the above values are valid for the specific geometry only, they may provide designers with the first view in the design process.

\section{Acknowledgement}

Support of the Czech Grant Agency under grant GACR No. 17-24769S is gratefully acknowledged.

\section{References}

Hafez, H. H., Temple, M. C. and Ellis, J. S. (1979) Pretensioning of single-crossarm stayed columns. J. Struct. Div. ASCE, 14362 ST2, pp. 359-375.

Lapira, L., Wadee, M. A. and Gardner, L. (2017) Stability of multiple-crossarm prestressed stayed columns with additional stay systems. Structures, 12, pp. 227-241.

Pichal, R. and Machacek, J. (2017) Experimental and numerical study of stayed steel columns, in: Engineering Mechanics 2017, Brno University of Technology, Brno, pp. 774-777.

Pichal, R. and Machacek, J. (2017) Buckling and post-buckling of prestressed stainless steel stayed columns. Engineering Structures and Technologies, 9, 2, pp. 63-69.

Pichal, R. and Machacek, J. (2018) Single-Crossarm Stainless Steel Stayed Columns" Advances in Technology Innovation, 3, 1, 9-16.

Saito, D. and Wadee, M. A. (2009) Numerical studies of interactive buckling in prestressed steel stayed columns. Eng. Struct., 31, 2, pp. 432-443.

Servitova, K. and Machacek, J. (2011) Analysis of stainless steel stayed columns, in: Proc. $6^{\text {th }}$ Int. Symp. Steel Structures (eds. Kim, W. B., Kim, K. D. and Sung-Won, Y.), Korean Society of Steel Construction, Seoul, pp. 874-881.

Wadee, M. A., Gardner L. and Osofero, A. I. (2013) Design of prestressed stayed columns. J. Construct. Steel Research, 80, pp. 287-298.

$\mathrm{Yu}, \mathrm{J}$. and Wadee, M. A. (2017) Mode interaction in triple-bay prestressed stayed columns. Int. Journal of Non-Linear Mechanics, 88, pp. 47-66. 